\title{
Abrasco: diversidade de atuação e trajetória do campo da saúde coletiva no Brasil
}

\section{Abrasco: the diversity of activities and trajectory of the field of public health in Brazil}

\author{
Luciana Dias de Lima \\ Pesquisadora, Escola Nacional de Saúde Pública Sergio Arouca (Ensp)/Fiocruz. \\ Rio de Janeiro - RJ - Brasil \\ luciana@ensp.fiocruz.br \\ Henrique Sant'Anna Dias \\ Doutorando, Programa de Pós-graduação em Saúde Pública/Ensp/Fiocruz. \\ Rio de Janeiro - RJ - Brasil \\ henriquesesrj@gmail.com
}

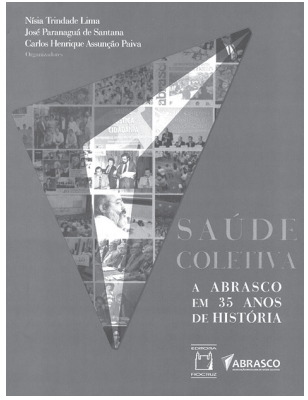

LIMA, Nísia Trindade; Paranaguá; PAIVA, Carlos Henrique Assunção (Org.). Saúde coletiva: a Abrasco em 35 anos de história. Rio de Janeiro: Editora Fiocruz. 2015. 324p. SANTANA, José

$\mathrm{O}$ conhecimento da história da Associação Brasileira de Saúde Coletiva (Abrasco) permite compreender a trajetória de conformação do campo da saúde coletiva no Brasil. Essa é a chave analítica para a leitura do livro Saúde coletiva: a Abrasco em 35 anos de história (Lima, Santana, Paiva, 2015). Como resultado, tem-se um panorama abrangente do campo, em termos de sua institucionalização e profissionalização como área de produção de conhecimento científico, e suas vinculações com os rumos da política e as transformações do sistema de saúde no país.

A obra está estruturada em 11 capítulos, reunindo contribuições de 26 autores de variadas inserções institucionais. Em geral, os capítulos dedicam-se a analisar em perspectiva histórica a atuação da entidade nos planos da política, da produção científica e do ensino. Essas múltiplas dimensões de atuação configuram-se de modo imbricado e em diálogo permanente, evidenciando o que se percebe como um consenso entre os autores: a Abrasco como uma associação científica com "papel militante".

No seu conjunto, os capítulos recorrem à fundação e ao papel desempenhado pela Abrasco ao longo de sua história. Destaque é dado aos atores/fundadores, aos posicionamentos e à conformação da agenda - política e científica - da associação e às suas diversas atividades institucionais, como congressos, publicações e participação junto aos órgãos governamentais e movimentos sociais.

De certa forma, é possível agrupar os capítulos segundo o enfoque principal de análise. Os três primeiros exploram principalmente as origens da saúde coletiva e a atuação política da 
Abrasco. O capítulo inicial reconstrói o processo de constituição do "espaço social da saúde coletiva", recuperando as condições históricas que o viabilizaram, as trajetórias e posições dos seus agentes fundadores. A criação da Abrasco e a atuação das suas diretorias aparecem como elementos relevantes do crescente questionamento e da ruptura com as práticas preexistentes de saúde pública e de medicina preventiva, nos anos 1970, configurando-se como ambientes de formulação de novas proposições da área.

A luta pela democracia, a defesa da reforma sanitária brasileira e do Sistema Único de Saúde (SUS) são os aspectos centrais dos dois capítulos seguintes, que destacam o protagonismo da ação política da Abrasco. São enfatizados os posicionamentos institucionais que conformam a agenda política da associação, as propostas e discussões da sua Comissão de Política e os registros de sua atuação na oitava Conferência Nacional de Saúde, ocorrida em 1986. No processo constituinte, instaurado em 1987, ressalta-se sua liderança, juntamente com o Centro Brasileiro de Estudos de Saúde (Cebes) nas proposições feitas à Subcomissão de Saúde e que influenciaram o texto constitucional. Tal protagonismo, interpretam os autores, mantém-se no período de implementação do SUS. O capítulo 3 apresenta, ainda, reflexões sobre a implantação da Comissão da Verdade da Reforma Sanitária Abrasco-Cebes, idealizada no contexto da Comissão Nacional da Verdade, com o objetivo de registrar e apurar as violações ocorridas durante o regime militar, a partir de 1964.

Na sequência, predominam as discussões sobre a atuação da Abrasco no contexto da produção do conhecimento científico. Enfatizam-se os desafios e as mudanças na divulgação científica por meio das revistas da associação, Ciência \& Saúde Coletiva e Revista Brasileira de Epidemiologia, criadas em 1996 e 1998, respectivamente. Além do registro dos momentos em que surgem os periódicos, realiza-se um apanhado dos seus objetivos, os avanços e desafios, bem como os temas dos seus editoriais e os assuntos presentes nos artigos publicados.

Os congressos da Abrasco têm a sua historiografia atualizada no quinto capítulo, dedicado aos eventos ocorridos entre 2006 e 2015, contemplando tanto os Congressos Brasileiros de Saúde Coletiva, conhecidos como "Abrascão", quanto aqueles organizados por áreas específicas: epidemiologia; ciências sociais e humanas em saúde; política, planejamento e gestão em saúde. São identificadas as inovações realizadas na organização dos congressos e as motivações que permeiam as escolhas dos temas e os conteúdos das "cartas" com os posicionamentos da associação.

Tais eventos constituem-se como referências e fontes de informação para temas abordados em outros capítulos, em especial os dois últimos, dedicados, respectivamente à conformação de uma agenda internacional da entidade, informada pelo seu reconhecimento internacional e o estabelecimento de parcerias na realização de eventos, como o Congresso Mundial de Saúde Pública; e às experiências mais recentes da Abrasco, no que diz respeito aos seus propósitos de fortalecimento do campo científico, da luta pela democratização da saúde e de organização interna.

A formação e o ensino em saúde coletiva, no contexto da profissionalização da área, ganha espaço em quatro diferentes capítulos do livro (6 a 9), que destacam: a experiência da criação do curso de graduação em saúde coletiva e a atuação do Fórum de Graduação da Abrasco; a trajetória da pós-graduação lato sensu e a inovação introduzida com a constituição da Agência de Acreditação Pedagógica dos cursos; a evolução dos programas 
de pós-graduação stricto sensu em saúde coletiva no Brasil, os avanços e desafios enfrentados no âmbito do sistema de avaliação da Capes e o papel do Fórum dos Coordenadores de Pós-graduação; e o desenvolvimento dos mestrados profissionais.

Por último, é apresentada uma seção dedicada às perspectivas e aos desafios da Abrasco na visão dos seus presidentes, em depoimentos coletados, em sua maioria, em seminário comemorativo da passagem dos 35 anos da entidade. Além disso, é disponibilizada rica seleção de imagens que registram, cronologicamente, os "personagens abrasquianos", os momentos históricos que marcam a atuação da Abrasco e seus materiais de divulgação e comunicação.

Em síntese, a abordagem histórica e institucional adotada no livro traz novos elementos para elucidação de aspectos distintivos do campo da saúde coletiva no Brasil. A diversidade de atuação da Abrasco expressa e, simultaneamente, favorece o desenvolvimento de um pensamento crítico, que se adensa e diversifica ao longo do tempo em função do seu próprio objeto - a dimensão social da saúde -, permitindo a conformação de uma ciência comprometida com a vida e politicamente engajada com a melhoria das condições de saúde da população.

\section{REFERÊNCIA}

LIMA, Nísia Trindade; SANTANA, José

Paranaguá; PAIVA, Carlos Henrique Assunção

(Org.).

Saúde coletiva: a Abrasco em 35 anos de história.

Rio de Janeiro: Editora Fiocruz. 2015.

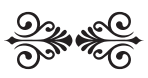

